DOI: $10.17957 / \mathrm{IJAB} / 15.1769$

http://www.fspublishers.org

\title{
Morphological and Molecular Characterization of Large-spored Alternaria Species Associated with Potato and Tomato Early Blight in Egypt
}

\author{
Sherif M. El-Ganainy ${ }^{1,2 *}$, Sozan E. El-Abeid ${ }^{3}$, Yosra Ahmed ${ }^{3}$ and Zafar Iqbal ${ }^{4}$ \\ ${ }^{1}$ Department of Arid Land Agriculture, College of Agriculture and Food Sciences, King Faisal University, Al-Ahsa, 31982, \\ Saudi Arabia \\ ${ }^{2}$ Vegetable Diseases Research Dept., Plant Pathology Research Institute, ARC, Giza, Egypt \\ ${ }^{3}$ Mycology Research \& Disease Survey, Plant Pathology Research Institute, ARC, Giza, Egypt \\ ${ }^{4}$ Central Laboratories, King Faisal University, Al-Ahsa, 31982, Saudi Arabia \\ *For correspondence: salganainy@kfu.edu.sa; sherifmsc2000@yahoo.com \\ Received 08 January 2021; Accepted 09 February 2021; Published 16 April 2021
}

\begin{abstract}
Early blight incurs huge losses to solanaceous crops at both pre- and post-harvest stages by reducing yields up to $35-78 \%$. Large-spored Alternaria spp. were isolated and characterized from the symptomatic tomato and potato plants. Morphological characterization revealed heterogeneity in the different traits of the isolates, which were subsequently confirmed by molecular characterization and two different Alternaria spp. viz. A. solani and A. linariae were characterized. A multi-locus phylogenetic analysis was conducted to infer the taxonomic position of the isolates within Alternaria spp. The five conserved genome regions used to infer phylogenetic lineage and evolutionary relationship were the internal transcribed spacer (ITS), the translation elongation factor $(T E F)$, the glyceraldehyde-3-phosphate dehydrogenase (GADPH), the major allergen Alt a1 (Alt al) and the RNA-polymerase 2 (RPB2) genes. All $A$. linariae isolates were closely related and formed a clade to $A$. linariae isolated from the United States. Similarly, A. solani isolates were closely related to each other and formed an independent clade indicating their unique nature. Koch's postulates were fulfilled for all the isolates. Among six different tested fungicides, aveet (azoxystrobin 5\% + mancozeb 70\%) inhibited the mycelial growth the most and saver (cymoxanil 5\% + chlorothalonil $37 \%$ ) the least. All the isolates infected tomato and potato leaves with varying severity except A. linariae isolate Egy-T2 was non-pathogenic on potato leaves, while the rest of $A$. linariae isolates were more aggressive. Here, we demonstrated that early blight in Egypt is caused by two different species of fungal pathogens, A. linariae and A. solani, and reported isolation of $A$. linariae from Egypt. (C) 2021 Friends Science Publishers
\end{abstract}

Keywords: Alternaria linariae; Alternaria solani; Early blight; Multi-locus phylogeny; Potato; Tomato

\section{Introduction}

Potato (Solanum tuberosum L.) and tomato (Solanum lycopersicum L.) are the most important vegetable cash crops in the world. Potato is the world's third mostproduced crop with an annual production of 368.17 million metric tons (MMT) (FAOSTAT 2018) and is grown on all continents except Antarctica (Birch et al. 2012). Tomato is the world's largest produced vegetable crop with 182.26 MMT annual production (FAOSTAT 2018) and its cultivation area has increased by $164 \%$ in the last 40 years with an increase of $314 \%$ in its consumption (Nicola et al. 2009). Potato is Egypt's second most cultivated crop with an annual production of about 5 million tons (FOASTAT 2018), while tomato is Egypt's top-ranked horticulture crop in terms of production and the area under cultivation (ca
161702 hectares) (FAOSTAT 2018). Globally, Egypt is the $5^{\text {th }}$ largest producer of tomatoes in the world with an annual production of 6.62 MMT (Siam and Abdelhakim 2018; Abdel-Motaal et al. 2020a). Both potatoes and tomatoes are Egypt's important sources of food, feed, livelihood and foreign exchange, with annual exports (both fresh and processed) amounting to 90,000 million tonns and 674,480 tons, respectively (Siam and Abdelhakim 2018). Nonetheless, the production of tomatoes and potatoes in Egypt is threatened by several biotic stresses, among which early blight disease is a leading threat to potatoes and tomatoes production. The disease is responsible for considerable yield losses worldwide and accounts for up to a 78\% reduction in yields (Gannibal et al. 2014; Adhikari et al. 2017). Early blight disease can infer losses of up to $20 \%$ to potatoes production and $78 \%$ to tomatoes production

To cite this paper: El-Ganainy SM, SE El-Abeid, Y Ahmed, Z Iqbal (2021). Morphological and molecular characterization of large-spored Alternaria species associated with potato and tomato early blight in Egypt. Intl J Agric Biol 25:1101-1110 
(Rotem 1994; Gannibal et al. 2014). Early blight induces characteristics symptoms of dark-colored spots, which are necrotic in the middle with a unique pattern of concentric rings, ridges and lesions on the leaves but can also spread to stem, twigs and fruits (Grigolli et al. 2011). The onset of symptoms initially appears on the basal and mature leaves as small, irregular or circular brown zonate lesions. These symptoms progress gradually to the upper leaves and then turn into dark colored spots with a characteristic "target-spot appearance" (Weber and Halterman 2012; Zheng et al. 2015). Severe infection can lead to twig drying, defoliation and premature fruit falling under favourable conditions (Khan et al. 2018) and the severity of infection usually turns into an epidemic in semi-arid areas with frequent and prolonged night dew (Rotem and Reichert 1964).

Alternaria solani was initially considered the sole species inducing early blight disease in solanaceous crops (Chaerani and Voorrips 2006; Gannibal et al. 2014). However, a range of physiological characteristics such as pathogenicity, cultural characteristics, phenetic and genetic polymorphisms observed within $A$. solani populations (Weber and Halterman 2012) led to the taxonomic revision of Alternaria species from Solanaceous hosts (Simmons 2000). Consequently, several new species related to early blight disease of potatoes and tomatoes were described (Simmons 2000, 2007). In addition, small-spored Alternaria spp. associated with foliar disease of potatoes and tomatoes were demonstrated as $A$. alternata, A. arborescens and $A$. tenuissima (Simmons 2000). Nonetheless, besides sharing striking similarities, A. solani isolated from tomato was referred to as A. tomatophila (Simmons 2000). Recently, isolates belonging to this species have been recategorized to a new species and referred to as A. linariae (Woudenberg et al. 2014).

Most of the studies demonstrating fungal characterization relied on morphological identification coupled to the molecular characterization. Using morphological identification along with multi-locus phylogenetic analysis is considered as a robust approach for fungal characterization. Several studies encompassing the molecular characterization of Alternaria species have demonstrated different genetic loci to infer the genetic and evolutionary relationship (Lawrence et al. 2013; Woudenberg et al. 2013; Javaid et al. 2016). The most widely used genetic loci include ITS, SSU rDNA, TEF, GADPH, RPB2 and Alt al (Woudenberg et al. 2014, et al. 2015; Javaid et al. 2018).

The most common measure to control early blight disease is the application of fungicides. The most commonly used fungicides belong to the Quinone inhibitor group. Different fungicides such as azoxystrobin, mancozeb, difenoconazole, chlorothalonil and carbendazim have been reported to curb early blight disease (Rosenzweig et al. 2008; Horsfield et al. 2010; Odilbekov et al. 2019). However, these fungicides have a very specific mode of action that can lead to the development of fungicide resistance (Leiminger et al. 2014; Odilbekov et al. 2019), and therefore, it is recommended that alternative fungicides be used or combined with other fungicides having different modes of action.

Several Alternaria spp. have been found infecting potatoes and tomatoes in Egypt and the growing diversity of the Alternaria spp. has changed the paradigm. The study demonstrated here was therefore aimed at deciphering the EB pathogen associated with potato and tomato plants by their morphological and molecular characterization. Our results, to our best knowledge and literature surveyed, demonstrated the isolation of $A$. linariae from tomato plants that have not yet been reported earlier in Egypt. However, a complete survey and an epidemiological study is a prerequisite to evaluate the threat associated with $A$. linariae to tomatoes and potatoes production in Egypt.

\section{Materials and Methods}

\section{Sampling and isolation of Alternaria species}

Tomato leaves, fruits and potato tubers exhibiting early blight symptoms, like dark-colored necrotic spots with a unique pattern of concentric rings, were surveyed. A total of 140 symptomatic samples, 20 from each location, were collected during the 2018-2019 crop seasons from major crop growing areas viz., Aswan, Beheira, Beni-suef, Giza, Kafr El-Sheik, Qena and Sharqia of Egypt (Table 1). The collected samples were sliced into small pieces (approx. $5 \times 5$ $\mathrm{mm}$ ) around the lesion and then surface sterilized for $2 \mathrm{~min}$ (min) in sodium hypochlorite $(2 \%)$ followed by excessive rinsing (2-3 times) with sterile distilled water (SDW). The cuttings were shifted onto Potato Dextrose Agar (PDA; Difco, Montreal, Canada) media supplemented with $100 \mathrm{mg}$ $\mathrm{L}^{-1}$ streptomycin sulphate and incubated at $25 \pm 1^{\circ} \mathrm{C}$ for 7 days. Growing colonies were observed on the isolated cuttings and, subsequently, colonies were sub-cultured onto PDA plates to yield purified culture. Pure culture of each grown isolate was obtained using the hyphal tip method and maintained at $4^{\circ} \mathrm{C}$ on PDA slants for subsequent study.

\section{Morphological characterization of the large-spored Alternaria species}

Purified fungal isolates were identified based on their morphological characters, including spore size, growth pattern and spore chain formation (Simmons 2007). Colony morphology (color and colony texture) was assessed on corn meal agar (CMA), malt extract agar (MEA), PDA and V8 juice agar (V8JA) media at $25^{\circ} \mathrm{C}$ for 10 days. To examine the spores, purified fungal isolates were grown on V8JA plates at $25^{\circ} \mathrm{C}$ for 7 days with $16 \mathrm{~h}$ of photoperiod. Aerial mycelia were removed and the colony surface was gently wounded to allow mycelia to produce spores and after 48 h, spores were examined (Langsdorf et al. 1990). A total of 50 fungal conidia were observed under a light 
microscope (Leica, CME Microscope Model 1349522X, U.S.A.) using differential interference contrast illumination, photographs were recorded and edited in the Adobe Illustrator (v. 23.0.5, 2019).

\section{DNA extraction, PCR amplification and sequencing}

Total genomic DNA extraction from seven fungal isolates was performed after following an amended Dellaporta extraction method (Dellaporta et al. 1983). About $100 \mathrm{mg}$ (fresh weight) of fungal mycelia were harvested by scraping the surface of the colony to extract the DNA. The quality and quantity of the extracted DNAs were assessed spectrophotometrically (NanoDrop 2000, Thermo Fisher Scientific, DE, U.S.A.) and adjusted to a concentration of 40 ng $\mu \mathrm{L}^{-1}$ in ultrapure water. The extracted DNA was aliquoted and stored at $-80^{\circ} \mathrm{C}$ until further use.

Five partial regions of the isolated fungal genome, the internal transcribed spacer region (ITS) was amplified with ITS4 and ITS5 primers, the translation elongation factor 1- $\alpha$ gene (Tefl) with EF1-688F and EF1-1251R primers, the glyceraldehyde 3-phosphate $(G A D P H)$ with Gpd_F and Gpd_R primers, RNA-polymerase 2 (RPB2) with RPB2$6 \mathrm{~F} / \mathrm{RPB} 2-7 \mathrm{cR}$ primers and the Alta1 region (Alta 1) with Alt-al-for and Alt-al-rev primers (Table 2). PCR amplification was achieved separately for each genomic region in a $25 \mu \mathrm{L}$ reaction containing $1 \mu \mathrm{L}$ of the fungal DNA extract (40 ng $\mu \mathrm{L}^{-1}$ of total DNA), 2.5 of $10 \mathrm{X} \mathrm{PCR}$ buffer (Biomatic, Life Technologies, U.S.A.), $2 \mathrm{mM} \mathrm{MgCl}$, $1.5 \mu \mathrm{L}$ of $10 \mu \mathrm{M}$ of each primer, $2.5 \mu \mathrm{L}$ of $10 \mathrm{~m} M \mathrm{dNTPs}$, $0.3 \mu \mathrm{L}$ of $5 \mathrm{U}$ Taq DNA Polymerase and the reaction was completed to $25 \mu \mathrm{L}$ with Nuclease-free water. All the PCR amplicons were completely sequenced (Macrogen Inc., South Korea).

\section{Phylogenetic analysis}

To infer the phylogenetic lineage and evolutionary relationship of the isolates, all the five genes (ITS, TEF, $G A P D H$, Altal and RPB2) were initially BLASTn searched (http://blast.ncbi.nlm.nih.gov/Blast.cgi) and Alternaria spp. showing the highest sequence similarity to the five genes were retrieved from GenBank for subsequent analysis (Table 1). Multiple sequence alignment was conducted using MUSCLE (Edgar 2004) and the evolutionary relationship was inferred by using the maximum likelihood (ML) algorithm after selecting the best fit Tamura-Nei (TN93+G+I) model (Tamura and Nei 1993) in MEGA X (Kumar et al. 2018). The phylogenetic dendrogram (1000 replicates of bootstrap) was constructed with an optimal tree having the highest log-likelihood -6928.26.

\section{Pathogenicity test on detached leaves}

Pathogenicity of the seven isolates of large-spored Alternaria spp. was evaluated under in vitro conditions by inoculating the detached leaflets of 30-days-old tomato (cv.
Super Strain B) and potato (cv. Spunta) plants. Fully expanded disease-free young leaflets of tomato and potato plants grown under greenhouse conditions were used after surface sterilization with sodium hypochlorite (2\%) and then washing with SDW. The spore suspension was prepared by pouring $10 \mathrm{~mL}$ of SDW into the sporulated isolates growing on V8JA plates, and the spores count was adjusted to $1 \mathrm{x}$ $10^{6}$ conidia/mL using a haemocytometer, then $20 \mu \mathrm{L}$ droplet was inoculated on the adaxial sides of the leaflets, while 20 $\mu \mathrm{L}$ SDW droplet was used as a negative control. Each inoculation was replicated seven times and the whole experiment was repeated twice. Inoculated leaflets were placed on sterilized Petri dishes harboring wet sterilized tissue papers and incubated at $25^{\circ} \mathrm{C}$ and $80 \%$ relative humidity with $12 \mathrm{~h}$ of photoperiod in the growth chamber. The inoculated leaflets were observed on daily basis and the symptoms on the leaves were recorded after seven days. Eventually, the re-isolation of Alternaria spp. from the inoculated leaves was carried out on PDA media to confirm the Koch's postulate (Sharma et al. 2004). A 0-5-point disease severity scale was followed (Vakalounakis 1983) and the disease severity index (DSI) was calculated as $" \mathrm{DSI} \%=[100 \times$ sum of all rating scales $] /(\mathrm{N} \times$ maximum disease scale), where $n$ is the number of the infected leaflets and $\mathrm{N}$ is the total number of leaves.

\section{Evaluation of selected fungicides on the isolated Alternaria spp.}

The poisoned food technique (Nene and Thapliyal 1993) was used to assess the efficacy of six different commercially available fungicides against the isolated Alternaria spp. (Table 3). Recommended/standard quantity of each fungicide was added aseptically to the molten PDA agar $\left(50^{\circ} \mathrm{C}\right)$ and control plates were devoid of any fungicide. The plates were inoculated aseptically with ten-day-old $5 \mathrm{~mm}$ mycelial disc and incubated at $25 \pm 2^{\circ} \mathrm{C}$ until the mycelial growth of the tested isolate covered the entire media in the control plates. Four replicates of each inoculation were used and the experiment was repeated twice. The diameter of the colonial radial growth was recorded for each treatment, a mean of four replicates was calculated, compared to the control and percent inhibition of mycelial growth was determined using the formula given by (Vincent 1947):

$$
\mathrm{I} \%=[(\mathrm{C}-\mathrm{T}) / \mathrm{C}] 100
$$

Where; I = Inhibition (\%),

$\mathrm{C}=$ the mean of colony growth $(\mathrm{mm})$ of the tested isolate in untreated control plates

$\mathrm{T}=$ the mean of colony growth $(\mathrm{mm})$ of the tested isolate in treated plates

\section{Data analysis}

To evaluate the pathogenicity of the fungal isolates and the effect of different fungicides, a completely randomized design was employed. ANOVA and least significant 
El-Ganainy et al. / Intl J Agric Biol, Vol 25, No 5, 2021

Table 1: Details of the Alternaria spp. isolates from Egypt with reference isolates and their accession numbers used in the study

\begin{tabular}{|c|c|c|c|c|c|c|c|c|c|}
\hline \multirow[t]{2}{*}{ Fungus } & \multirow[t]{2}{*}{ Isolate Code } & \multirow[t]{2}{*}{ Host, plant organ } & \multirow[t]{2}{*}{ Origin } & \multirow{2}{*}{$\begin{array}{l}\text { Collection } \\
\text { date }\end{array}$} & \multicolumn{5}{|c|}{ GenBank accession No. } \\
\hline & & & & & ITS & $T e f-1$ & GAPDH & Alt a 1 & $R P B 2$ \\
\hline A. linariae & Egy-T1 & Solanum lycopersicum, fruit & Giza- Egypt & 2018 & MT996270 & MT996277 & MT996256 & MT996249 & MT996263 \\
\hline A. linariae & Egy-T2 & S. lycopersicum, leaf & Kafr el-sheikh & 2018 & MT996271 & MT996278 & MT996257 & MT996250 & МТ996264 \\
\hline A. linariae & Egy-T3 & S. lycopersicum, leaf & Aswan- Egypt & 2018 & MT996272 & MT996279 & MT996258 & MT996251 & MT996265 \\
\hline A. solani & Egy-T4 & S. lycopersicum, leaf & Qena- Egypt & 2018 & MT996273 & MT996280 & MT996259 & MT996252 & MT996266 \\
\hline A. linariae & Egy-T5 & S. lycopersicum, leaf & Sharqia- Egypt & 2019 & MT996274 & MT996281 & MT996260 & MT996253 & МТ996267 \\
\hline A. linariae & Egy-T6 & S. lycopersicum, leaf & Beheira- Egypt & 2019 & MT996275 & MT996282 & MT996261 & MT996254 & MT996268 \\
\hline A. solani & Egy-P1 & Solanum tuberosum, tuber & Giza- Egypt & 2019 & MT996276 & MT996283 & MT996262 & MT996255 & МT996269 \\
\hline A. allii & CBS 107.28 & Allium cepa, leaf spot & Puerto Rico & - & KJ718100 & KJ718449 & KJ717954 & KJ718620 & KJ718274 \\
\hline A. allii & CBS 225.76 & Allium porrum, leaf & Italy & - & KJ718102 & KJ718451 & KJ717956 & KJ718622 & KJ718276 \\
\hline A. grandis & CBS 109158 & S. tuberosum, leaf & U.S.A., Pennsylvania & - & KJ718239 & EU130547 & JQ646341 & JQ646425 & KJ718414 \\
\hline A. grandis & CBS 116695 & S. tuberosum, leaf & U.S.A., Pennsylvania & - & KJ718241 & KJ718587 & KJ718070 & KJ718748 & KJ718416 \\
\hline A. limicola & CBS 483.90 & Citrus aurantiifolia, leaf & Mexico, Colima & - & KJ718178 & KJ718526 & JQ646329 & JQ646413 & KJ718351 \\
\hline A. limicola & CBS 117360 & Citrus spp. & Mexico, Jalisco & - & KJ718179 & KJ718527 & KJ718023 & - & KJ718352 \\
\hline A. linariae & CBS 109156 & Solanum lycopersicum, leaf & U.S.A., Indiana & - & KJ718183 & KJ718531 & JQ646347 & JQ646431 & KJ718356 \\
\hline A. multirostrata & CBS 712.68 & Richardia scabra, floral bract & U.S.A., Georgia & - & KJ718195 & EU130546 & JQ646362 & KJ718704 & KJ718368 \\
\hline A. multirostrata & CBS 713.68 & Richardia scabra, floral bract & U.S.A., Georgia & - & KJ718196 & KJ718542 & KJ718034 & KJ718705 & KJ718369 \\
\hline A. passiflorae & CBS 113.38 & Passiflora edulis & Australia, South Queensland & - & KJ718207 & KJ718553 & JQ646353 & JQ646437 & KJ718380 \\
\hline A. passiflorae & CBS 166.77 & Capsicum frutescens, leaf & New Zealand & - & KJ718208 & KJ718554 & KJ718044 & KJ718716 & KJ718381 \\
\hline A. solani & CBS 111.41 & Solanum aviculare, leaf & & - & KJ718237 & KJ718583 & KJ718067 & KJ718744 & KJ718411 \\
\hline A. solani & CBS 116442 & Vicia faba & New Zealand & - & KJ718240 & KJ718586 & KJ718069 & KJ718747 & KJ718415 \\
\hline A. solani & CBS 109157 & Solanum tuberosum & U.S.A. & - & KJ718238 & KJ718585 & GQ180080 & KJ718746 & KJ718413 \\
\hline A. brassicicola & CBS 118699 & Brassica oleracea & U.S.A. & - & KC584259 & KC584642 & KC584103 & & KC584383 \\
\hline
\end{tabular}

Table 2: Nucleotide sequence of the primers used in the study

\begin{tabular}{|c|c|c|c|}
\hline Locus Name & Primer* & Sequence (5'-3') & Reference \\
\hline \multirow[t]{2}{*}{ ITS region } & ITS4 & TCCTCCGCTTATTGATATGC & White et al. (1990) \\
\hline & ITS5 & GGAAGTAAAAGTCGTAACAAGG & \\
\hline \multirow[t]{2}{*}{ Tef-1 } & $\mathrm{EF} 1-688 \mathrm{~F}$ & CGGTCACTTGATCTACAAGTGC & Alves et al. (2008) \\
\hline & EF1-1251R & CCTCGAACTCACCAGTACCG & \\
\hline \multirow[t]{2}{*}{$G A D P H$} & $\begin{array}{l}\text { Gpd_F } \\
\text { Gpd_R }\end{array}$ & $\begin{array}{l}\text { CAACGGCTTCGGTCGCATTG } \\
\text { GCCAAGCAGTTGGTTGTGC }\end{array}$ & Berbee et al. (1999) \\
\hline & Alt-al-for & ATG CAG TTC ACC ACC ATC GC & Hong et al. (2005) \\
\hline Alt a 1 & Alt-a1-rev & ACG AGG GTG AYG TAG GCG TC & \\
\hline$R P B 2$ & $\begin{array}{l}\text { RPB2-6F } \\
\text { FRPB2-7cR }\end{array}$ & $\begin{array}{l}\text { TGG GGK WTG GTY TGY CCT GC } \\
\text { CCC ATR GCT TGY TTR CCC AT }\end{array}$ & Liu et al. (1999). \\
\hline
\end{tabular}

${ }^{*} \mathrm{~F}$ for the forward primer and $\mathrm{R}$ for the reverse primer

Table 3: Details of the used fungicides, their active ingredients and standard concentrations in in vitro evaluation

\begin{tabular}{|c|c|c|c|}
\hline Fungicides No. & Trade name & Active ingredient & Conc. $*$ \\
\hline A & Aveet $75 \%$ WG & Azoxystrobin5\% + mancozeb $70 \%$ & $1 \mathrm{~g} \mathrm{~L}^{-1}$ \\
\hline $\mathrm{D}$ & Decent plus $32 \% \mathrm{SC}$ & Difenoconazole $12.5 \%$ + Azoxystrobin $20 \%$ & $0.4 \mathrm{~mL} \mathrm{~L}^{-1}$ \\
\hline $\mathrm{C}$ & Cuprofix CM & Cymoxanil $2.5 \%$ + Metalic copper $15 \%$ & $1.5 \mathrm{~g} \mathrm{~L}^{-1}$ \\
\hline $\mathrm{R}$ & Ridomil Gold R 26.89\%WG & Metalaxyl M2\% + Metalic copper $14.19 \%$ & $3.3 \mathrm{~g} \mathrm{~L}^{-1}$ \\
\hline $\mathrm{P}$ & Prevex-N72\% SL & Propamocarb hydrochloride & $3 \mathrm{~mL} \mathrm{~L}^{-1}$ \\
\hline S & Saver $42 \% \mathrm{SC}$ & Cymoxanil 5\% + Chlorothalonil $37 \%$ & $3 \mathrm{~mL} \mathrm{~L}^{-1}$ \\
\hline
\end{tabular}

difference (LSD) tests were conducted to determine the statistical significance at $P<0.05$. The collected data were statistically analyzed using the MSTAT-C program (v 2.10).

\section{Results}

\section{Isolation and identification of Alternaria spp.}

Microscopic examination of 63 purified isolates of Alternaria spp. revealed that 56 isolates were small spored with abundant sporulation on the PDA media and were morphologically assigned to A. alternata and A. tenuissima while 7 Alternaria isolates failed to produce spores on the PDA media. All the small-spored Alternaria isolates were excluded in this study, whereas different media including V8JA, CMA and MEA were used to yield spores from the remaining 7 Alternaria spp. Among the tested media, V8JA increased the mycelial growth followed by MEA, PDA and CMA, respectively, and sporulation was observed only on V8JA two days post mycelium removal. Whereas PDA and MEA media were best suited to induce colony pigmentation. Detailed microscopic examination of morphological characters on V8JA like sporulation patterns, conidia size and shape, and beak length revealed the presence of two groups of large-spored Alternaria spp. The identification of the purified isolates was achieved after following the set-criteria for the sporulation of the Alternaria genus. The spores of Alternaria isolates in this 


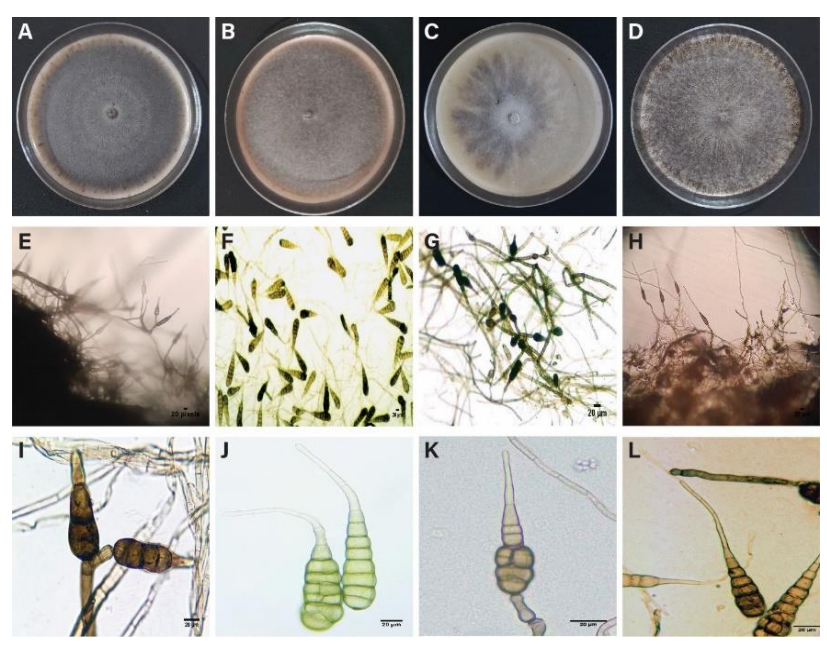

Fig. 1: Colonies, sporulation patterns and conidia of four Alternaria spp. isolates. Colonies of Egy-P1 (A), Egy-T1 (B), Egy-T3 (C), and Egy-T4 (D) observed on V8J agar plates; their sporulation patterns $(\mathbf{E}-\mathbf{H})$, and their conidia (I-L)

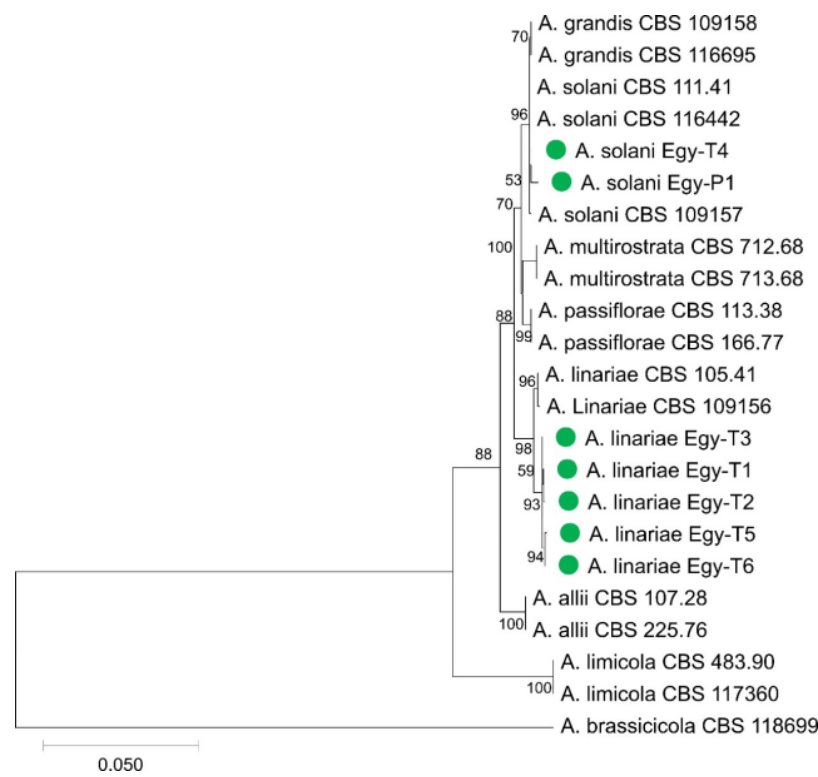

Fig. 2: Phylogenetic tree illustrating the relationship between $A$. solani and $A$. linariae isolates (highlighted with a green circle) and other Alternaria spp. The phylogenetic tree is based on the nucleotide sequences of five genes (ITS, TEF, GAPDH, ALT and $R P B 2$ ) and was produced in MEGAX using the maximumlikelihood method and the best-fit model TN93+G+I. Only bootstrap values greater than $50 \%$ are shown

study exhibited a high-level of resemblance to the largespored Alternaria spp. associated with tomato and potato groups and accepted as $A$. solani and $A$. linariae. The isolates produced olive green and brown conidia with conidium ellipsus body shape and different numbers of cells per conidium (Table 4). Conidia were generally individual, rarely in short chains, straight or slightly curved, or with conidium ellipsus body tapering to an average beak length 27.91-135.01 $\mu \mathrm{m}$. Conidia of A. linariae produced beak length ranged from 64.09 to $135.01 \mu \mathrm{m}$, while body length ranged from 33.64 to $136.22 \mu \mathrm{m}$ with a width of 17.20 to $28.51 \mu \mathrm{m}$ (Fig. 1 and Table 4). While two isolates of $A$. solani beak length ranged from 27.91 to $116.06 \mu \mathrm{m}$, with a conidium, the total length of 70.63 to $77.61 \mu \mathrm{m}$ and width of 16.94-25.05 $\mu \mathrm{m}$ (Table 4). Colonies were thick grey to black with scattered aerial mycelium, often branched and simple conidiophores with multi-septate conidia constitute $0-7$ transverse septa and 2-10 longitudinal septa.

\section{Molecular characterization of the large-spored Alternaria spp.}

To characterize two different types of conidia, all isolates were subjected to molecular characterization by DNAsequencing. PCR amplicons of highly-variable to moderately variable genes, ITS ( $\sim 550 \mathrm{bp})$, Tef-1 ( 220 bp), GADPH ( 580 bp), Alt al ( 450 bp) and RPB2 ( 760 bp) were achieved from all isolates and then completely sequenced. All sequences were submitted to NCBI GenBank database (accession numbers mentioned in Table 1) and BLASTn searched for the most closely related sequences. To infer the phylogenetic lineage and evolutionary relationship of the isolates, a multi-locus phylogeny was performed and sequences of only those Alternaria strains, whose all five genes sequences were available at GenBank, were included in the analysis, while A. brassicola (CBS 118699) was used as an outlier to validate the tree (Fig. 2). Neighbor-joining (NJ) and maximum likelihood (ML) algorithms produced similar tree topologies but ML produced clades with higher bootstrap values, therefore ML tree is shown. The isolates namely $A$. solani (Egy-P1 and Egy-T4) were closely related and grouped with A. solani CBS 116442 (an isolate from Netherland). The other isolates namely A. linariae (Egy-T1, Egy-T2, Egy-T3, Egy-T5 and Egy-T6) formed a multiphyletic group together and were closely related to other isolates of A. linariae (CBS 109156 [isolated from the United States] and CBS 105.41[isolated from Netherland]). Within the A. linariae group, a clear split was observed that formed 3 subgroups with moderate-tohigh bootstrap values (Fig. 2).

\section{Pathogenicity tests on detached leaves}

All the tested isolates of A. linariae and A. solani produced early blight symptoms on tomato and potato detached leaves irrespective of their host plant origin. While control leaflets, inoculated with sterile distilled water remained asymptomatic (Fig. 3 and 4). However, a wide range of pathogenesis was observed when symptoms were evaluated (Table 5). Initially, the symptoms appeared as yellow flecks on the $4^{\text {th }}$ day of inoculation, which then increased in size and became sunken lesion. Subsequently, the lesions 
El-Ganainy et al. / Intl J Agric Biol, Vol 25, No 5, 2021

Table 4: Morphological characteristics of A. linariae and A. solani isolates

\begin{tabular}{|c|c|c|c|c|c|c|c|}
\hline \multirow[t]{2}{*}{ Isolate Code } & \multirow[t]{2}{*}{ species } & \multirow[t]{2}{*}{ Colony colour* } & \multicolumn{2}{|c|}{ Body** } & \multirow{2}{*}{$\begin{array}{l}\text { Beak } \\
\text { length } \mu \mathrm{m}\end{array}$} & \multicolumn{2}{|l|}{ Septa } \\
\hline & & & Length $\mu \mathrm{m}$ & width $\mu \mathrm{m}$ & & Long. & Tran. \\
\hline Egy-T1 & A. linariae & Greyish to black with red pigment & 98.84 & 22.46 & 111.82 & $6-10$ & $1-7$ \\
\hline Egy-T2 & A. linariae & Greyish-white, - No pigmentation & 106.13 & 20.93 & 104.76 & $4-9$ & $0-4$ \\
\hline Egy-T3 & A. linariae & dark grey to black with pale pigment & 33.64 & 17.20 & 64.09 & $3-5$ & $1-2$ \\
\hline Egy-T4 & A. solani & dark grey to black with dark pigment & 77.61 & 16.94 & 116.06 & $5-11$ & $3-7$ \\
\hline Egy-T5 & A. linariae & Greyish to black with red pigment & 113.18 & 21.27 & 117.77 & $4-7$ & $0-4$ \\
\hline Egy-T6 & A. linariae & Greyish to black with red pigment & 136.22 & 28.51 & 135.01 & $6-10$ & $2-6$ \\
\hline Egy-P1 & A. solani & Black with pale red pigment & 70.63 & 25.05 & 27.91 & $2-5$ & $0-3$ \\
\hline
\end{tabular}

* colony colour was recorded on fungal culture grown on V8JA at $25+2^{\circ} \mathrm{C}$ for 10 days

*** measurement of conidial structure

Table 5: Pathogenicity test of A. solani and A. linariae isolates on potato and tomato detached leaves under in vitro conditions

\begin{tabular}{lllc}
\hline Alternaria species & Isolates Code & \multicolumn{2}{c}{ Disease severity index (DSI\%) } \\
\cline { 3 - 4 } A. linariae & & Tomato leaves & Potato leaves \\
A. linariae & Egy-T1 & 54.3 & 37.1 \\
A. linariae & Egy-T2 & 68.6 & 0.0 \\
A. solani & Egy-T3 & 45.7 & 11.4 \\
A. linariae & Egy-T4 & 22.9 & 17.1 \\
A. linariae & Egy-T5 & 51.4 & 51.4 \\
A. solani & Egy-T6 & 65.7 & 42.9 \\
LSD & Egy-P1 & 37.1 & 45.7 \\
\hline
\end{tabular}

Table 6: Effect of different fungicides on the mycelial growth of $A$. linariae and A. solani isolates

\begin{tabular}{|c|c|c|c|c|c|c|c|c|c|c|c|c|c|c|}
\hline \multirow[t]{4}{*}{ Isolate Code } & \multicolumn{14}{|c|}{ Fungicides } \\
\hline & \multicolumn{14}{|c|}{ Inhibition of mycelial growth (\%) } \\
\hline & \multicolumn{2}{|c|}{ (A) Aveet } & \multicolumn{2}{|c|}{ (D) Decent plus } & \multicolumn{2}{|c|}{ (C) Cuprofix CM } & \multicolumn{2}{|c|}{ (R) Ridomil gold R } & \multicolumn{2}{|c|}{ (P) Prevex } & \multicolumn{2}{|c|}{ (S) Saver } & \multicolumn{2}{|l|}{ Control } \\
\hline & $\mathrm{G}^{*} \mathrm{~mm}$ & $\mathrm{I} \% * *$ & $\mathrm{G} \mathrm{mm}$ & $\mathrm{I} \%$ & $\mathrm{G} \mathrm{mm}$ & $\mathrm{I} \%$ & $\mathrm{G} \mathrm{mm}$ & $\mathrm{I} \%$ & $\mathrm{G} \mathrm{mm}$ & $\mathrm{I} \%$ & $\mathrm{G} \mathrm{mm}$ & $\mathrm{I} \%$ & $\mathrm{G} \mathrm{mm}$ & $\mathrm{I} \%$ \\
\hline Egy-T2 & 5 & 94.4 & 12 & 86.7 & 43 & 52.2 & 18 & 80 & 70 & 22.2 & 68 & 24.4 & 90 & 0 \\
\hline Egy-T3 & 0 & 100 & 0 & 100 & 46 & 48.9 & 40 & 55.6 & 78 & 13.3 & 90 & 0 & 90 & 0 \\
\hline Egy-T4 & 0 & 100 & 0 & 100 & 53 & 41.1 & 27 & 70 & 79 & 12.2 & 88 & 2.2 & 90 & 0 \\
\hline Egy-T5 & 0 & 100 & 19 & 78.9 & 60 & 33.3 & 28 & 68.9 & 50 & 44.4 & 74 & 17.8 & 90 & 0 \\
\hline Egy-P1 & 0 & 100 & 17 & 81.1 & 12 & 86.7 & 23 & 74.4 & 90 & 0 & 85 & 5.6 & 90 & 0 \\
\hline LSD & Fungi $=4$ & & fungi & $=4.292$ & Fungi X & ide $=1$ & & & & & & & & \\
\hline
\end{tabular}

* growth of Alternaria isolates (mm) on PDA media (mean of four replicates)

**Inhibition of the mycelial growth $(\%)$

progressed to a grayish tint in the center surrounded by a yellow halo. All five isolates of $A$. linariae were virulent to tomato leaves with the DSI ranged from 51.4 to $68.6 \%$ and 11.4 to $51.4 \%$ on potato leaves (Table 5). A. linariae isolate Egy-T2 was found to be the most aggressive isolate on tomato leaves as it induced more severe symptoms with the highest disease severity index $68.6 \%$, while it did not exhibit any pathogenicity on potato leaves and the inoculated leaves remained asymptomatic. Two of the isolates of A. solani (Egy-T4 and Egy-P1) produced typical early blight symptoms on both tomato and potato leaves. Egy-P1 was more severe on both tomato and potato leaves than Egy-T4 whereas DSI of Egy-T4 was $22.9 \%$ on tomato leaves and $17.1 \%$ on potato leaves, while DSI of Egy-P1 was $37.1 \%$ on tomato leaves and $45.7 \%$ on potato leaves. Generally, two different patterns of symptoms were induced by $A$. solani and $A$. linariae isolates. For instance, $A$. linariae induced wide and irregular lesions that covered most of the expanded area of the inoculated leaves, while $A$. solani produced limited lesions around the inoculated areas (Fig. 4). All Alternaria isolates were re-isolated successfully from all leaf lesions to fulfill Koch's postulate. Generally, all A. linariae isolates were more aggressive on tomato than potato leaves as compared to $A$. solani isolates.

\section{Evaluation of the inhibitory effect of selected fungicides on the isolates}

The inhibitory effect of different commercially available fungicides (Aveet, Decent plus, Cuprofix CM, Ridomil Gold R, Prevex, Saver) on the hyphal extension and colony growth of seven Alternaria isolates was investigated (Table 6). All the tested fungicides had significant delaying or inhibiting effect on the mycelial growth of Alternaria spp. However, Aveet 75\% WG (azoxystrobin 5\% + mancozeb $70 \%$ ) had strong inhibitory effect and was able to reduce the growth of all the isolates ranging from 86.7 to $100 \%$, followed by Decent plus (difenoconazole $12.5 \%+$ azoxystrobin 20\%) whose inhibitory effect ranged from 78.9 to $100 \%$, Ridomil Gold R (metalaxyl M 2\% + metalic copper $14.19 \%$ ) inhibited from 55.6 to $80.0 \%$ and Cuprofix CM (cymoxanil 2.5\% + metalic copper 15\%) 

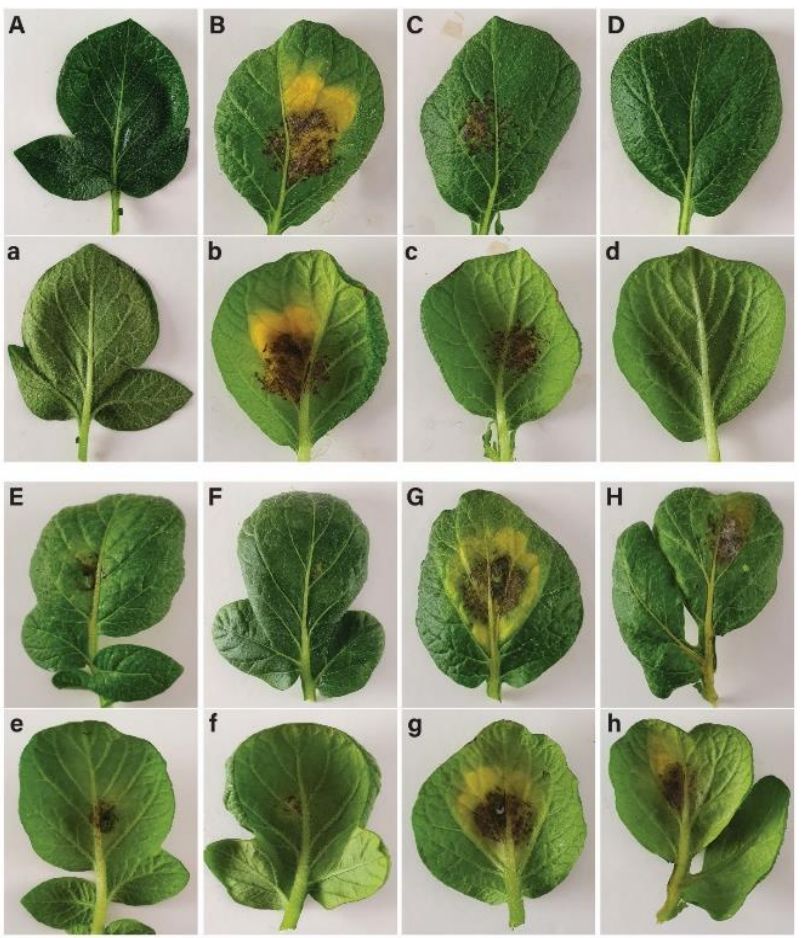

Fig. 3: Early blight symptoms exhibited by all the isolates on potato detached leaves. Both sides of the leaves, adaxial sides (mentioned in capital letters) and abaxial sides (mentioned in small letters) are shown. The leaves were either non-inoculated (A, a) or inoculated with Egy-P1 (B, b), Egy-T1 (C, c), Egy-T2 (D, d), Egy-T3 (E, e), Egy-T4 (F, f), Egy-T5 (G, g), and Egy-T6 $(\mathbf{H}, \mathbf{h})$. The experiment was conducted using detached of 30-dayold plants of potato (cv. Spunta). Leaves were photographed at 7 days post-inoculation and disease severity (DS) was scored on a 0-5-point rating system

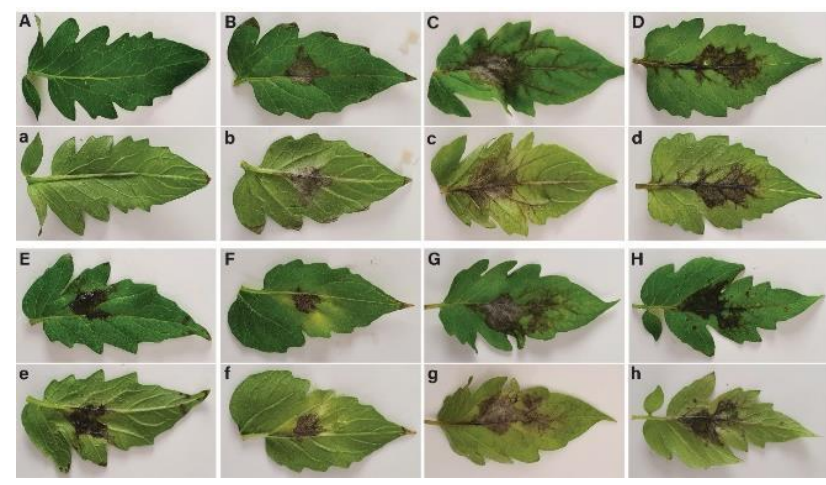

Fig. 4: Early blight symptoms exhibited by all the isolates on tomato detached leaves. Both sides of the leaves, adaxial sides (mentioned in capital letters) and abaxial sides (mentioned in small letters) are shown. The leaves were either non-inoculated (A, a) or inoculated with Egy-P1 (B, b), Egy-T1 (C, c), Egy-T2 (D, d), Egy-T3 (E, e), Egy-T4 (F, f), Egy-T5 (G, g), and Egy-T6 $(\mathrm{H}, \mathrm{h})$. The experiment was conducted using detached of 30-dayold plants of tomato (cv. Super strain B). Leaves were photographed at 7 days post-inoculation and disease severity (DS) was scored on a $0-5$-point rating system from 33.3 to $67.8 \%$, respectively. Nonetheless, Prevex (Propamocarb hydrochloride) and Saver (cymoxanil 5\% + chlorothalonil $37 \%$ ) had the least effect on the mycelial growth of Alternaria isolates. All the tested isolates exhibited a small degree of variations in mycelial growth towards the tested fungicides.

\section{Discussion}

Alternaria spp. are not only a major limiting factor to tomatoes and potatoes production, but also causes postharvest spoilage to tomatoes and potatoes (El-Mougy and Abdel-Kader 2009; Adss et al. 2017). Several Alternaria spp. have been found infecting potatoes and tomatoes in Egypt, including A. arborescens, A. alternata, A. phragmospora and A. solani (Abada et al. 2008; El-AbdKareem et al. 2009; Ashour et al. 2012; El Gobashy et al. 2018; Hussein and Voigt 2019; Attia et al. 2020). Among these, $A$. solani is the most prevalent and leading cause of $\mathrm{EB}$ and $A$. alternata is the most prevalent species associated with leaf blight, whereas $A$. arborescens has been found to be the least prevalent in Egypt (El Gobashy et al. 2018; Hussein and Voigt 2019). A very recent study reported the first identification of $A$. phragmospora causing early blight disease in tomato plants (Abdel-Motaal et al. 2020a, b). The results of the study demonstrated that the population structure of large-spored Alternaria spp. associated with early blight disease in Egypt has a more complex structure than previously observed. The first identification of $A$. linariae from tomatoes and the identification of $A$. solani from tomatoes and potatoes suggest that the mounting scenario could be alarming. However, this is far from a conclusion, as this study was based on a few isolates, but the identification of $A$. linariae from most of the collected tomato samples from different areas demonstrated a changing paradigm. Both of these Alternaria spp. have previously been found associated with early blight disease of tomatoes and potatoes in Russia and Algeria (Gannibal et al. 2014; Ayad et al. 2019).

As the morphological characterization of Alternaria spp. is a challenging and often misleading task due to the striking similarities among the conidia of several species and the cultural features of some Alternaria spp., such as $A$. solani, are unstable (Rotem 1994). Similarly, at the molecular level, the use of a single gene region is insufficient to distinguish various Alternaria spp. or even the same group of individual isolates (Woudenberg et al. 2013, 2015; El Gobashy et al. 2018). To circumvent this problem, a multi-locus phylogeny was followed which demonstrated that the use of multiple genes, such as GAPDH, ITS, RPB2, OPA10-2, Alt a 1 , endoPG and $K O G 1058$, could separate all the isolates and species belonging to Alternaria (Woudenberg et al. 2014). Therefore, the same strategy was followed in this study and five genes (ITS, TEF, GAPDH, ALT and RPB2) were included which revealed a higher genotype level in Alternaria spp. and easily distinguish our isolates. 
A comparative study with representative strains helped to ascertain that the two Alternaria spp., A. linariae and $A$. solani, are found associated with tomato and potato plants. A varying degree of coloration was exhibited by our isola $A$. linariae and $A$. solani on different media. Morphological characters of $A$. solani or A. linariae on V8JA media were quite close to those defined by Simmons (2007) and V8JA was the only media that induced sporulation of all the isolates. To achieve closely related morphological identification, the beak length and its branching and conidial body size were studied. Sporulation was conducted on V8JA plates to distinguish the two species, but it is important to take into account that the conidia size and shape depend on the used substratum. Compared to V8JA, both species produced two types of beaks, long and short. Similar findings have been appraised for other large-spored Alternaria species, for example, A. calendulae (Simmons 2007). Cultural characters have been used previously to identify different Alternaria spp. especially A. solani populations (Ivanuk and Palilova 1996), additionally, it is noteworthy that the cultural characters of A. solani are unstable (Rotem 1994).

Pathogenicity assay and cross-inoculation of detached tomato and potato leaves revealed that $A$. linariae infected all the inoculated tomato and potato leaves except Egy-T2 isolate which was avirulent on the potato. Variation of severity between all the tested isolates was observed indicating that there are different types of aggressiveness in the Egyptian population of Alternaria spp. However, there was a strong infection and association with tomato plants as the induced symptoms were more severe. A. linariae was able to infect the leaves of the potato, but with less aggressiveness than the tomatoes. This may indicate that $A$. linariae isolates are acclimatizing rapidly under Egyptian environmental conditions. While $A$. solani also infected both tomatoes and potato leaves with a moderate degree of aggressiveness. These results are consistent with earlier reports in which $A$. linariae showed strong association and aggressiveness with tomato leaves but weak with potato leaves (Rodrigues et al. 2010; Gannibal et al. 2014). However, A. solani was moderately aggressive to tomato and potato leaves (Ivanuk and Palilova 1996; Gannibal et al. 2014). In contrast to our observation, $A$. solani and $A$. linariae have been found infecting their respective potato or tomato hosts in Algeria, but cross-inoculations on detached leaflets had shown that the aggressiveness towards the two host leaves varies depending on the isolate but not on the specific fungal species (Ayad et al. 2019). Thus, our results are congruent to earlier studies that both two Alternaria spp. can infect both tomatoes and potato plants but exhibit severe symptoms in their respective hosts.

Early blight disease is prevalent wherever potatoes and tomatoes are cultivated. The disease is considered difficult to control since only a few cultivars having a strong resistance are available (Xue et al. 2019). The most effective control measure is the frequent use of fungicides at the early stage of the growing season (Horsfield et al. 2010; Odilbekov et al. 2019). An effective control strategy is a key prerequisite for achieving a laconic control over early blight disease. This research was further extended to evaluate the inhibitory effects of six commercial fungicides on the growth of $A$. linariae and $A$. solani isolates under in vitro conditions. Although all of the tested fungicides significantly inhibited mycelial growth, but the systemic fungicide, Aveet 75\% WG (azoxystrobin 5\% + mancozeb $70 \%$ ), substantially inhibited the colony growth up to $100 \%$ in five of the seven tested isolates of $A$. solani and $A$. linariae. The next most effective fungicide was Decent plus $32 \%$ SC (Difenoconazole 12.5\% + Azoxystrobin 20) which inhibited colony growth ranging from 78.9 to $100 \%$. Difenoconazole, along with boscalid and pyraclostrobin, was reported to exhibit better performance against $A$. solani in 2014 but not in 2017 , later the underlying reason for poor performance was found to link with mutations and the lower infection pressure in 2017 (Odilbekov et al. 2019). The protective mancozeb and the systemic azoxystrobin and difenoconazole materials are widely used fungicides against A. solani in Solanaceous crops (Rosenzweig et al. 2008; Horsfield et al. 2010). The current finding confirms the reports of several earlier studies that reported the efficacy of Mancozeb on inhibiting the growth of $A$. solani isolated from tomato (Gondal et al. 2012; Singh et al. 2018). Wang et al. (2008) showed that sixty isolates of $A$. solani were sensitive to difenoconazole using the mycelial growth method. Horsfield et al. (2010) also reported that azoxystrobin and difenoconazole were highly effective in controlling EB under field conditions.

The symptoms induced by $A$. solani and A. linariae isolates on the detached leaves of potatoes and tomatoes did not differ significantly from that of the infected tomato and potato plants collected from the field. Similar results have been obtained for A. tenuissima, A. alternata and A. solani (Zheng et al. 2015). However, a few studies found contrasting results, where the symptoms induced by $A$. alternata and $A$. solani differ substantially from those of the early blight disease symptoms observed in field plants. The observed difference may be due to the detached leaf (DL) assay, as no correlation has been observed between the pathogenicity of the DLassay in greenhouse conditions and/or field conditions (Foolad et al. 2000; El Gobashy et al. 2018). However, both greenhouse and field tests have a clear correlation, suggesting that whole-plant inoculation is the best method for assessing the pathogenicity of Alternaria spp. associated with early blight disease. The reason behind this difference is unclear yet and requires further investigations.

Summarizing all our results, such as the aggressiveness and adaptability of $A$. linariae to tomato and potato plants along with aberrant climatic changes, we can suggest that $A$. linariae, either alone or with $A$. solani, could potentially cause substantial losses to tomato and potato production in Egypt. However, a comprehensive 
disease-survey, assessment of the susceptibility of the available tomato and potato cultivars, synergistic interactions between $A$. linariae and A. solani, evaluation of pathogenicity under greenhouse conditions and characterization of $A$. linariae is a prerequisite to assess the mounting scenario.

\section{Conclusion}

The underlying pathogens associated with early blight disease in Egypt are found to be more diverse than previously recognized. A higher level of pathogenicity of $A$. linariae on potato and tomato plants revealed its potential to become a wide-spread and leading cause of early blight disease, either alone or combining with other Alternaria spp. Further studies are necessary to reveal the aggressiveness, distribution, symptoms pattern in the field and difference in fitness of the species.

\section{Acknowledgments}

The authors extend their appreciation to the Deputyship for Research \& Innovation, Ministry of Education in Saudi Arabia for funding this research work through project number IFT 20023.

\section{Author Contributions}

SME and SEE isolated the pathogen and evaluated the fungicides. YA wrote the discussion section. ZI and SME performed molecular analysis. SME, SEE and YA drafted the first version of the manuscript. ZI draw figures and drafted the final manuscript which was approved by all the authors.

\section{Conflicts of Interest}

The authors declare that they have no conflict of interest.

\section{Data Availability}

The data will be made avaialble on acceptable requests to the corresponding author.

\section{Ethics Approval}

Not applicable.

\section{References}

Abada KA, S Mostafa, MR Hillal (2008). Effect of some chemical salts on suppressing the infection by early blight disease of tomato. Egypt $J$ Appl Sci 23:47-58

Abdel-Motaal F, N Kamel, S El-Zayat, M Abou-Ellail (2020a). Early blight suppression and plant growth promotion potential of the endophyte Aspergillus flavus in tomato plant. Ann Agric Sci 65:117-123
Abdel-Motaal F, N Kamel, S El-Zayat, M Abou-Ellail (2020b). First report of Alternaria phragmospora causing early blight disease of Lycopersicon esculentum in Egypt. J Biol Sci 3:1-8

Adhikari P, Y Oh, DR Panthee (2017). Current status of early blight resistance in tomato: An update. Intl J Mol Sci 18; Article 2019

Adss I, H Hamza, E Hafez, H Heikal (2017). Enhancing tomato fruits postharvest resistance by salicylic acid and hydrogen peroxide elicitors against rot caused by Alternaria solani. J Agric Chem Biotechnol 8:1-8

Alves A, P Crous, A Correia, A Phillips (2008). Morphological and molecular data reveal cryptic species in Lasiodiplodia theobromae. Fung Divers 28:1-13

Ashour A, TA Rahman, H Badawy, N Dib (2012). Chemical control of tomato early blight disease. Egypt J Phytopathol 40:149-162

Attia MS, GS El-Sayyad, MA Elkodous, AI El-Batal (2020). The effective antagonistic potential of plant growth-promoting rhizobacteria against Alternaria solani-causing early blight disease in tomato plant. Sci Hortic 266; Article 109289

Ayad D, D Aribi, B Hamon, A Kedad, P Simoneau, Z Bouznad (2019). Distribution of large-spored Alternaria species associated with potato and tomato early blight according to hosts and bioclimatic regions of Algeria. Phytopathol Mediterr 58:139-149

Berbee ML, M Pirseyedi, S Hubbard (1999). Cochliobolus phylogenetics and the origin of known, highly virulent pathogens, inferred from ITS and glyceraldehyde-3-phosphate dehydrogenase gene sequences. Mycologia 91:964-977

Birch PRJ, G Bryan, B Fenton, EM Gilroy, I Hein, JT Jones, A Prashar, MA Taylor, L Torrance, IK Toth (2012). Crops that feed the world 8 Potato: are the trends of increased global production sustainable? Food Secur 4:477-508

Chaerani R, RE Voorrips (2006). Tomato early blight (Alternaria solani): the pathogen, genetics, and breeding for resistance. J Gen Plant Pathol 72:335-347

Dellaporta S, J Wood, J Hicks (1983). A rapid method for DNA extraction from plant tissue. Plant Mol Biol Rep 1:19-21

Edgar RC (2004). MUSCLE: multiple sequence alignment with high accuracy and high throughput. Nucl Acids Res 32:1792-1797

El-Abd-Kareem F, FM Abd-El-Faten, YO Fotouh (2009). Integrated treatments between humic acid and sulfur for controlling early blight disease of potato plants under field infection. Res J Agric Biol Sci 5:1039-1045

El-Mougy N, M Abdel-Kader (2009). Salts application for suppressing potato early blight disease. J Plant Prot Res 49:353-361

El Gobashy SF, WZA Mikhail, AM Ismail, A Zekry, A Moretti, A Susca, AS Soliman (2018). Phylogenetic, toxigenic and virulence profiles of Alternaria species causing leaf blight of tomato in Egypt. Mycol Progr 17:1269-1282

FAOSTAT (2018). Food and Agriculture Organization of the United Nations Statistics Division. Available: http://faostat3.fao.org/home/E (Accessed: September 14, 2020)

Foolad M, N Ntahimpera, B Christ, G Lin (2000). Comparison of field, greenhouse, and detached-leaflet evaluations of tomato germplasm for early blight resistance. Plant Dis 84:967-972

Gannibal PB, AS Orina, NV Mironenko, MM Levitin (2014). Differentiation of the closely related species, Alternaria solani and A. tomatophila, by molecular and morphological features and aggressiveness. Eur J Plant Pathol 139:609-623

Gondal AS, M Ijaz, K Riaz, AR Khan (2012). Effect of different doses of fungicide (mancozeb) against alternaria leaf blight of tomato in tunnel. J Plant Pathol Microbiol 3; Article 1000125

Grigolli JFJ, MM Kubota, DP Alves, GB Rodrigues, CR Cardoso, DJH deSilva, ESG Mizubuti (2011). Characterization of tomato accessions for resistance to early blight. Crop Breed Appl Biotechnol 11:174-180

Hong SG, RA Cramer, CB Lawrence, BM Pryor (2005). Alt a 1 allergen homologs from Alternaria and related taxa: analysis of phylogenetic content and secondary structure. Fung Genet Biol 42:119-129

Horsfield A, D Wilson, S Paton, T Wicks, K Davies (2010). Effect of fungicide use strategies on the control of early blight (Alternaria solani) and potato yield. Aust Plant Pathol 39:368-375 
Hussein MA, K Voigt (2019). Phylogenetic and enzymatic variability of Alternaria species isolated from various substrates in Qena governorate of Upper Egypt. Arch Phytopathol Plant Prot 52:530-541

Ivanuk V, A Palilova (1996). Structure of Alternaria solani (Ell. et Mart.) Jones et Gront population- the pathogen of potatoes alternariosis and its dynamic in Byelorussa. Mikol Fitopatol 30:66-74

Javaid A, GR Shahzad, N Akhtar, D Ahmed (2018). Alternaria leaf spot disease of broccoli in Pakistan and management of the pathogen by leaf extract of Syzygium cumini. Pak J Bot 50:1607-1614

Javaid A, N Akhtar, A Khan, A Shoaib (2016). New host record of Alternaria brassicicola infecting triangle palm (Dypsis decaryi) in Pakistan. J Anim Plant Sci 26:1894-1898

Khan M, R Wang, B Li, P Liu, Q Weng, Q Chen (2018). Comparative Evaluation of the LAMP assay and PCR-based assays for the rapid detection of Alternaria solani. Front Microbiol 9; Article 2089

Kumar S, G Stecher, M Li, C Knyaz, K Tamura (2018). MEGA X: Molecular evolutionary genetics analysis across computing platforms. Mol Biol Evol 35:1547-1549

Langsdorf G, N Furuichi, N Doke, S Nishimura (1990). Investigations on Alternaria solani Infections: Detection of alternaric acid and a susceptibility-inducing factor in the spore-germination fluid of $A$. solani. J Phytopathol 128:271-282

Lawrence DP, PB Gannibal, TL Peever, BM Pryor (2013). The sections of Alternaria: formalizing species-group concepts. Mycologia 105:530-546

Leiminger JH, B Adolf, H Hausladen (2014). Occurrence of the F129L mutation in Alternaria solani populations in Germany in response to QoI application, and its effect on sensitivity. Plant Pathol 63:640-650

Liu YJ, S Whelen, BD Hall (1999). Phylogenetic relationships among ascomycetes: evidence from an RNA polymerse II subunit. Mol Biol Evol 16:1799-1808

Nene YL, PN Thapliyal (1993). Fungicides in Plant Disease Control, 3 Edition. International Science Publisher, New York, USA

Nicola S, G Tibaldi, E Fontana (2009). Tomato production systems and their application to the tropics. In: International Symposium on Tomato in the Tropics, Villa de Leyva, Colombia, 2009, pp: 27-34. International Society for Horticultural Science (ISHS), Leuven, Belgium

Odilbekov F, E Edin, H Mostafanezhad, H Coolman, LJ Grenville-Briggs, E Liljeroth (2019). Within-season changes in Alternaria solani populations in potato in response to fungicide application strategies. Eur J Plant Pathol 155:953-965

Rodrigues T, M Berbee, E Simmons, CRC Carine, A Reis, L Maffia, E Mizubuti (2010). First report of Alternaria tomatophila and A. grandis causing early blight on tomato and potato in Brazil. New Dis Rep 22:28-28

Rosenzweig N, G Olaya, ZK Atallah, S Cleere, C Stanger, WR Stevenson (2008). Monitoring and tracking changes in sensitivity to azoxystrobin fungicide in Alternaria solani in wisconsin. Plant Dis 92:555-560
Rotem J (1994). The genus Alternaria biology, epidemiology, and pathogenicity. APS Press, St. Paul, Minnesota, USA

Rotem J, I Reichert (1964). Dew-a principal moisture factor enabling early blight epidemics in a semiarid region of Israel. Plant Dis Rep 48:211-215

Sharma P, SR Sharma, M Sindhu, A Kaur (2004). A detached leaf technique for evaluation of resistance in cabbage and cauliflower against three major pathogens. Ind J Plant Pathol 22:112-114

Siam G, T Abdelhakim (2018). Analysis of the tomato value chain in Egypt and establishment of an action plan to increase its efficiency. Doctoral Dissertation, p: 118. CIHEAM-IAMM, Montpellier, France

Simmons EG (2007). Alternaria: an identification manual. CBS Fungal Biodiversity Centre, Utrecht, The Netherlands

Simmons EG (2000). Alternaria themes and variations (244-286) species on Solanaceae. Mycotaxon 75:1-115

Singh VP, RU Khan, D Pathak (2018). In vitro evaluation of fungicides, bio-control agents and plant extracts against early blight of tomato caused by Alternaria solani (Ellis and Martin) Jones and Grout. Intl J Plant Prot 11:102-108

Tamura K, M Nei (1993). Estimation of the number of nucleotide substitutions in the control region of mitochondrial DNA in humans and chimpanzees. Mol Biol Evol 10:512-526

Vakalounakis DJ (1983). Evaluation of tomato cultivars for resistance to Alternaria blight. Ann Appl Biol 102:138-139

Vincent JM (1947). Distortion of fungal hyphæ in the presence of certain inhibitors. Nature 159:850-850

Wang Hq, JS Tian, QP Yan (2008). Comparison of the sensitivity of Alternaria solani which causing tomato late blight to seven fungicides and its baseline-sensitivity to difenoconazole. Pesticides Shenyang 47:294-296

Weber B, DA Halterman (2012). Analysis of genetic and pathogenic variation of Alternaria solani from a potato production region. Eur J Plant Pathol 134:847-858

White TJ, T Bruns, S Lee, J Taylor (1990). Amplification and direct sequencing of fungal ribosomal RNA genes for phylogenetics. PCR Protoc Guide Meth Appl 18:315-322

Woudenberg JHC, MF Seidl, JZ Groenewald, MD Vries, JB Stielow, BPHJ Thomma, PW Crous (2015). Alternaria section Alternaria: species, formae speciales or pathotypes? Stud Mycol 82:1-21

Woudenberg JHC, M Truter, J Groenewald, P Crous (2014). Large-spored Alternaria pathogens in section Porri disentangled. Stud Mycol 79:1-47

Woudenberg JHC, JZ Groenewald, M Binder, PW Crous (2013). Alternaria redefined. Stud Mycol 75:171-212

Xue W, KG Haynes, X Qu (2019). Characterization of early blight resistance in potato cultivars. Plant Dis 103:629-637

Zheng HH, J Zhao, TY Wang, XH Wu (2015). Characterization of Alternaria species associated with potato foliar diseases in China. Plant Pathol 64:425-433 